\title{
Establish the Platform of Idle Goods - Focus on Left-behind Children
}

\author{
Siyu Yu \\ Electrical and Electronic Engineering Department, North China Electric Power University, China \\ winccey@163.com
}

Keywords: Left-behind children; Idle materials; Public welfare; Online and offline

\begin{abstract}
At the same time of China's growing, the phenomenon of left-behind children has quietly become a serious social problem, which has attracted the attention of a great of the CPC central committee and the state council. In the graduation period, how to deal with the accumulation of the university graduates materials has become their biggest worry, and at the same time, improperly handing the materials has caused great waste. On the one hand is a tremendous waste of materials, on the other hand is the thirst for supplies. This project is aimed to build a bridge to connect both of them.
\end{abstract}

\section{Project Origins}

Left-behind children due to long-term lack of the factors such as the parents' care and the guide of professional teachers, which lead to that left-behind children are unable to properly handle their negative emotions. They live in the poor areas, and education and life supplies are scarce. They cannot get age-appropriate books to read, and are even serious lack of school supplies. Among those reasons, it greatly reduces the children's learning interests and motivations. What is worse? A vicious cycle of young adults to become migrant workers and their kids into left-behind children happens over and over again. [1] In the graduation period, how to deal with the accumulation of the university graduates materials has become their biggest worry. [2] According to statistics, in 2014, national college graduates with idle books or clothes are up to $88.89 \%$ of total graduates, and more than $67.82 \%$ graduates finally choose to discard processing. This large group of graduates caused a great waste because of their improperly handling their idle materials and goods. [3]

The project can make maximize use of idle goods. The project addresses the idle goods as a springboard and accurate set up the platform between idle materials and goods and rural education public welfare funds, which makes both parties benefit. At the same time, by introducing the business model into the project, it is easy to change the past traditional simple donation activities. By collecting idle materials and goods for sale, to establish a perfect idle supplies and supply sales model to help graduates to deal with their materials and goods. According to the seller's willingness and striping out the project operating costs out of the selling price will be as public welfare funds. The money will be used to donate age-appropriate books with quality guarantee for left-behind children, build school library management mechanism, set up reading promoting, enhance the level of mental health of left-behind children, and strengthen rural students' self-esteem, self-confidence and independent problem solving skills. As for the unsold materials and goods, they will be distributed to left-behind children family after disinfection. In this way, the project improves the survival condition materially, and provide good material guarantee for their education condition.

What's more? The project from local colleges and universities to local communities and make full use of local social resources. Solving the local social problems by using local resources and power is the best way to help. And then, the project will spread from one place to the whole country, making full use of resources and power from all the places and produce independent regional sustainable support. In this way, the whole country will form a project network and a virtuous cycle. In other word, the project is sustainable and replicable, self hematopoiesis.

Thus, the project can make get maximum use of the old materials, and improve the bad living and education condition of poor mountainous left-behind children. 


\section{Description of Project}

Colleges and universities have a large number of graduates every year, [4] a large number of the graduates due to their improperly handling their idle materials and goods, which has caused tremendous waste of materials. When seasons change each year, there will be a big part of personal idle goods, no longer used by the residents. And most of these materials are still useful. [5] The project's recipients, the left-behind children in the poor areas, they are severe lack of supplies but cannot afford to buy them. [6] But due to the information gap between donors and left-behind children, it leads to that the two cannot achieve effective communicate. [7] At the same time, a lot of public welfare organizations are unable to provide the feedback of donation in time, and finally lead to that the donors cannot get to know the donations usage. [8]

Now the project has a lot of volunteers working at the first line. Through the project rural work teams of volunteers, they can release recipient needs to donors and authenticate feedback in time. Not only filling up the information gap between donors and recipients, but also implement the symmetry of information. What's more? It can also promote the public welfare value and make it maximization, and users can look up for their every donated money or materials and goods usage details in time, so as to realize the supervision of the public welfare organizations. It is not hard to find that the project can achieve the transparency of public goods and the standardization of the public welfare industry.

At the same time, the project adopts the way of offline promotion to cooperate with universities. Based on colleges and universities to spread radiation into the surrounding community, and then into each region. And in this way, the whole country will form a complete project network. By making full use of resources and power from all the places to solve the left-behind children problem and produce independent regional sustainable support.

Combine online and offline part of the project, and ultimately make the collection of donating, fundraising, selling, communicating, project cooperating and docking, managing, and other functions as a public welfare community, making full use of resources and the power to help left-behind children.

\section{Project Introduction}

The project is divided into two parts: offline part and online part, combining both parts to solve left-behind children education problem and idle material and goods handling problems in the colleges and universities and community. Through the idea of idle material and goods sales or donations, fill up the information gap between left-behind children and donors and involve grading related ones comprehensive score. Build mature public welfare community, and combine government, NGO, recipients and the media as an enterprise alliance. Ultimately make the collection of donating, fundraising, selling, communicating, project cooperating and docking, managing, and other functions as a whole. 


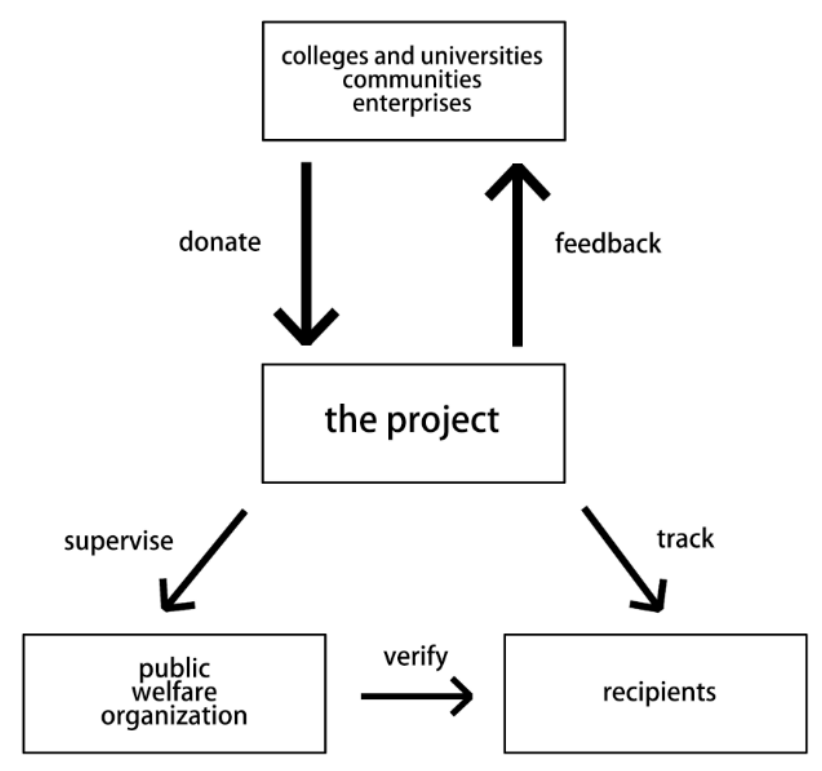

Figure 1. Mode pattern of the project

Offline Part. Regard colleges and universities and communities as starting points. Users can complete registration and selling application requests on the online platform. Colleges and universities undertake to recruit volunteers (with a focus on the college students), and volunteers are responsible for regular door-to-door pickup, inspection, entry database, and etc. All the materials and goods will be sold together in the intensive offline sale activity. According to the seller's willingness to draw $40 \%, 60 \%, 80 \%$ or $100 \%$ out of the whole selling proceeds as public welfare funds, which can be chosen by users to use in specific or not specific donation directions. As for the left part proceeds from the activities (not including the donation part), users can get the money by online withdrawing or cash settlement at the scene. As for the unsold materials and goods, which users want to take back, will be sent back to users by volunteers.

Public welfare funds from the intensive offline sale activity will be used to donate age-appropriate books with quality guarantee for left-behind children, build school library management mechanism, set up reading promoting, enhance the level of mental health of left-behind children, and strengthen rural students' self-esteem, self-confidence and independent problem solving skills. As for the unsold materials and goods, they will be distributed to left-behind children family after disinfection. In this way, the project improves the survival condition materially, and provide good material guarantee for their education condition. After the public welfare materials and goods donation, volunteers working at the first line will provide implement feedback in time and return to visit those families on a regular basis.

Based on colleges and universities to spread radiation into the surrounding community, the project provides the opportunity to participate in public welfare for the public, making the idea of everyone welfare more popular and enlarging the team for supporting left-behind children bigger. Radiate from region to region to form the project network. By making full use of resources and power from all the places to solve the left-behind children problem and produce independent regional sustainable support. And finally spread the public welfare concept.

Online Part. Users can complete registration and selling application requests on the online platform, then users can choose the selling proceeds donation proportion and directions. Volunteers will regularly do door-to-door pickup, accomplish the secondary sales and manage materials and goods for users.

Before the activity, all the unsold materials and goods will be put a bar code and scanned into the database in order to track. Users can check online to view the materials and goods they sell, the selling price and donations usage at anytime.

At the end of the current sale activity, the project will transfer the selling proceeds (except donation part) into users' account, and users' can also choose to settle accounts at the scene. If users 
want to take back their unsold materials and goods, they may apply on the online platform. As for the unsold materials and goods, which users want to take back, will be sent back to users by volunteers.

The project has a lot of volunteers working at the first line. Through the project's rural work teams of volunteers, they can release recipient needs to donors and authenticate feedback in time. People in need are able to independently seek help, and people who want to help are able to realize point-to-point donation. Volunteers are responsible for following up the need information on the online platform. Donors and recipients are allowed to grade and comment on the program they involve, implementation of personnel and the implementing agencies. Not only filling up the information gap between donors and recipients, but also implement the symmetry of the information. It can also promote the public welfare value and make it maximization.

Users who participate in public welfare projects can get the corresponding points. Points can be used for the required services. Another way to gain points is to finish the required services on the platform. The platform also can generate the public certificate automatically as the motivation of volunteers.

Public welfare organizations can apply to undertake welfare activities. Incomes gained from the activities belong to the organizers, but the profits must be used for public welfare and under the project's supervision.

Public welfare organizations can publish their own projects, looking for funds and other support. Relevant ones can participate in the activities the public welfare organizations released on the online platform, openly grade and evaluate the project. According to those ways, public welfare organizations and their project are under comprehensive quantitative assessment. The project can use this method to promote the development of industry and establish the social credibility.

\section{Project Objectives}

The project has objectives as follow:

1. Improve left-behind children living and education condition.

2. The most convenient and reliable way for users to solve the problem of idle material processing, at the same time provide an opportunity for the public to participate in public welfare. Let public welfare become less complicated and distant.

3. Filling up the information gap between donors and recipients, realize the information symmetry and promote public welfare value maximization.

4. Build scoring supervision mechanism, help the public welfare organizations to establish credibility and promote the development of the industry.

5. Build public welfare community combining donating, fundraising, selling, communicating, project cooperating and docking, managing, and other functions.

6. By making full use of resources and power from all the places to solve the left-behind children problem and produce independent regional sustainable support. And finally spread the public welfare concept.

\section{Project Light Spot}

Caring for Left-behind Children. Donating age-appropriate books with quality guarantee for left-behind children, build school library management mechanism, set up reading promoting, and enhance the level of mental health of left-behind children.

Idle Materials Processing. Help users to process idle materials and goods reasonably and effectively, and make materials and goods attain their maximum value.

Filling up the Information Gap. The project has a lot of volunteers working at the first line. Through the project's rural work teams of volunteers, they can release recipient needs to donors and authenticate feedback in time. Not only fill up the information gap between donors and recipients, but also implement the symmetry of information. It can also promote the public welfare value and make it maximization. 
Public Supervision. Build public scoring mechanism, add relevant ones into follow-up evaluation system, and evaluate public welfare organization with comprehensive quantitative methods.

Public Welfare Community. Build mature public welfare community, and combine government, NGO, recipients, the media as an enterprise alliance and resource integration, and build public welfare community combining donating, fundraising, selling, communicating, project cooperating and docking, managing, and other functions.

Public Welfare Concept. Promote progresses of the social public welfare industry.

\section{Conclusion}

Public welfare entrepreneurship is the inevitable trend of the social development, and public welfare activities will be widespread support.

The project will continue to address the idle materials and goods as a springboard, connect the public welfare organization, volunteers and left-behind children, and effectively support the development of rural education. Let the left-behind children get better living conditions and education conditions, at the same time improve their mental health level. Enhance public understanding of left-behind children and get more involved in, and spread the idea public welfare concept.

\section{Reference:}

[1] https://m.baidu.com/mip/c/www.360doc.cn/mip/286133691.html

[2] J. Wan, X.J. Su and D.M. Zhu: The investigation of ways of college students dealing with materials [J]. Study Monthly, Vol.8 (2014) No.8, p.89-90

[3] https://wenku.baidu.com/view/58bc4ad7240c844769eaeedb.html

[4] http://m.mnw.cn/news/china/1194094.html

[5] http://www.dydaily.com.cn/2016/1217/21618.shtml

[6] http://wap.sanwen8.cn/subject/ceghyhi.html

[7] http://finance.chinanews.com/ny/2014/05-26/6209769.shtml

[8] http://society.people.com.cn/n/2015/0331/c136657-26774192.html 